\title{
Comparison of the effects of dietary factors in the management and prophylaxis of migraine
}

\author{
Beyazit Zencirci \\ Department of Anesthesiology \\ and Reanimation, Medical Faculty \\ of Sutcu Imam University, \\ Kahramanmaras, Turkey
}

This article was published in the following Dove Press journal: Journal of Pain Research

22 July 2010

Number of times this article has been viewed
Correspondence: Beyazit Zencirci M Akif Inan Mah. Alparslan Turkes Bulvari, Seyhan Apt. No: 209 D: 5 Merkez, 46050-Kahramanmaras, Turkey Tel +90-344-2258300

Fax +90-344-2258303

Email bzencirci@fastmail.fm
Abstract: Migraine is defined as a disorder characterized by intermittent headache episodes, accompanied with nausea, photophobia and/or phonophobia. Pharmacological therapy is in accordance with the severity of pain and may include acute, prophylactic and most commonly both approaches. The aim of the acute therapy is stopping or alleviating the attack or progression of the pain and, in case of a migraine attack that has started, lessening the pain. Preventive therapy aims to reduce attack frequency and severity. This study was designed to evaluate the effect of dietary factors in the management and prophylaxis of migraine in cases diagnosed as having migraine disorder according to the 2003-IHS criteria. Fifty consecutive Turkish patients (13 men, 37 women) with diagnosis of migraine were randomly divided into two groups for treatment protocols with the written approval of the ethics committee. The cases in the first group (K) were treated with metoprolol, vitamin $\mathrm{B}_{2}$ (riboflavin), and naproxen sodium just at the aura or at the beginning of the attacks. The cases in the second group (D) were also supplied with a comprehensive dietary list arranged by our algology clinic in addition to the same medication protocol. There were no demographic differences between the cases $(P>0.05)$. VAS scores were lower in group D than group $\mathrm{K}(P<0.01)$, and also the migraine attack frequencies and monthly amounts of analgesic consumed amounts were also statistically significantly less. It was concluded that beta-blocker and riboflavin therapy supplemented with a convenient diet with appropriate alternatives in patients with migraine disorder was associated with statistically significant decreases in headache frequency, intensity, duration and medication intake.

Keywords: migraine, food intake, trigger

\section{Introduction}

Migraine is defined as a disorder characterized by intermittent headache episodes, accompanied with nausea, photophobia and/or phonophobia. ${ }^{1}$ Migraine attacks seem to result from pathophysiological mechanisms activated by specific trigger factors. The recurrence of migraine attacks may depend either on a reduced threshold or on particularly strong or frequent trigger factors or both. ${ }^{2}$ Biochemical research has provided evidence for certain physiologic characteristics in migraineurs, which have been proposed as predisposing factors for migraine. These include platelet serotonin (5-HT) metabolism, platelet activation, increased sensitivity to nitric oxide (NO) donors, reduced levels of metabolic enzymes, abnormal opiate receptor function, and electro-encephalographic (EEG) abnormalities. ${ }^{3}$

Pharmacological therapy, in accordance with the severity of pain, may include acute or prophylactic and most commonly both approaches. Acute therapy is stopping or alleviating the attack or progression of the pain and, in case of a migraine 
attack that has started, attempts to lessen the pain. Preventive treatment is indicated when the attacks are long lasting, severe and disabling and do not respond to acute treatments. ${ }^{4}$ Preventive therapy aims to reduce attack frequency and severity. ${ }^{5}$ The preventive treatment for migraine includes beta-blockers, antidepressants, calcium channel antagonists, serotonin antagonists, non-steroid anti-inflammatory drugs (NSAIDs), riboflavin (vitamin $\mathrm{B}_{2}$ ) at high doses and anticonvulsant drugs. ${ }^{6}$

An understanding of the aura and headache components of migraine provide a basis for the potential mechanisms of action of dietary triggers. Dietary migraine triggers may influence the pathophysiology of migraine at one or more phases of the migraine attack. They could affect the cerebral cortex, trigeminal nerve, brainstem trigeminal nuclei, thalamus, and brainstem or limbic pathways. The chemical trigger may stimulate neuroreceptors, cause release of neurotransmitters, or have a direct effect on neurons within the trigeminovascular migraine pathways. ${ }^{7}$

We conducted our study on 50 patients who were diagnosed with migraine [according to the 2003-International Headache Society (IHS) criteria ${ }^{8}$ (Table 1)]. In our research, we could not find any studies previously conducted with an extended diet list covering foodstuffs that are acknowledged to trigger migraine attacks. Thus, by completely removing some foodstuffs that we listed as triggering migraine headaches in various studies (having regard to dietary habits of Turkish society) from the daily diet lists of patients, we wanted to observe the effect on the consumption of analgesic medicines used for migraine headaches (recurrence and severity).

\section{Method}

With the written approval of the ethics committee, we started our study with 56 patients. However, 6 patients left the study or were ineligible for various reasons. Therefore 50 consecutive Turkish patients (13 men, 37 women) with diagnosis of migraine were randomly divided into 2 groups for treatment protocols. Cases with menstruational migraine were excluded from the study. Patients in each group were well informed about their diseases and the treatment modalities were applied.

Patients in the first group (Group K) were treated with metoprolol (120 mg/day), vitamin $\mathrm{B}_{2}$ (riboflavin $600 \mathrm{mg}$, 3 times a day), and naproxen sodium (550 mg) just at the aura or at the beginning of the attacks.

In addition to being provided with the same medication protocol, patients in the second group (Group D) were also supplied with a comprehensive dietary list (Table 2) arranged by our algology clinic. Furthermore, patients were also informed about the visual analog scale (VAS) and keeping a daily pain diary (DPD). They were asked to record their headache VAS scores, attack frequencies and severities and also naproxen sodium consumption starting from the beginning of the therapy.

Patients were recalled for control examinations every 15 days and their data (with special attention to their DPD) were recorded throughout a year.

All data were collected in an Excel ${ }^{\circledR}$ spread sheet for documentation. For statistical analysis, SPSS $13.0^{\circledR}$ for Windows (LEAD Technologies Inc, USA, 2004) was used. The Mann-Whitney U test was used to compare the differences between demographic data of patients such as age, length and weight; and Chi square test was used to compare the

Table I IHS criteria for the diagnosis of migraine

\begin{tabular}{|c|c|}
\hline Migraine without aura & Migraine with aura \\
\hline A 5 attacks fulfilling criteria $B-D$, and not attributed to another disorder & $\begin{array}{l}\text { A } 2 \text { attacks fulfilling criteria } B \text { and } C \text { and not attributed to another } \\
\text { disorder }\end{array}$ \\
\hline B Attacks lasting 4-72 hours (untreated or unsuccessfully treated) & $\begin{array}{l}\text { B Aura consisting of } \geq \mathrm{I} \text { of the following fully reversible symptoms but } \\
\text { no motor weakness: }\end{array}$ \\
\hline$C$ Headache has $\geq 2$ of the following characteristics: & $B_{1}$ Visual symptoms (flickering lights, spots/lines, and/or loss of vision) \\
\hline C, Unilateral location & $B_{2}$ Sensory symptoms (ie, "pins and needles" and/or numbness) \\
\hline $\mathrm{C}_{2}$ Pulsating quality & $\mathrm{B}_{3}$ Dysphasic speech disturbance \\
\hline \multicolumn{2}{|l|}{$\mathrm{C}_{3}$ Moderate or severe intensity (inhibits or prohibits daily activities) } \\
\hline $\mathrm{C}_{4}$ Aggravation by, or causing avoidance of, routine physical activity & $C \geq 2$ of the following: \\
\hline D During headache $\geq I$ of the following: & $C_{1}$ Homonymous visual symptoms and/or unilateral sensory \\
\hline$D_{1}$ Nausea and/or vomiting & symptoms \\
\hline \multirow[t]{2}{*}{$D_{2}$ Photophobia and phonophobia } & $\begin{array}{l}\mathrm{C}_{2} \text { Aura develops gradually over } \geq 5 \mathrm{~min} \text { and/or different aura } \\
\text { symptoms occur in succession over } \geq 5 \mathrm{~min}\end{array}$ \\
\hline & $\mathrm{C}_{3}$ Each symptom lasts $\geq 5 \mathrm{~min}$ and $\leq 60 \mathrm{~min}$ \\
\hline
\end{tabular}

Adapted from Cephalalgia. ${ }^{8}$ 
Table 2 Dietary list used for the patients in our algology clinic

\begin{tabular}{|c|c|}
\hline Foods to avoid/limit & Alternatives \\
\hline \multicolumn{2}{|l|}{ Beverages } \\
\hline Cola & Non-cola soft drinks \\
\hline Coffee & No more than I cup \\
\hline Tea & No more than 2 cups \\
\hline Chocolate drinks or cocoa & Non-chocolate drinks \\
\hline Alcoholic beverages, red wine in particular & Vodka, Sauterne or Riesling wines \\
\hline \multicolumn{2}{|l|}{ Fruit juices, decaffeinated drinks, flavored waters should be preferred } \\
\hline \multicolumn{2}{|l|}{ Dairy products } \\
\hline Milk & Low-fat or skim milk \\
\hline \multicolumn{2}{|l|}{ Buttermilk and cream } \\
\hline Cream & Butter/margarine \\
\hline Cheddar, Brie, processed cheeses, aged cheeses (Parmesan, Romano), fats, lard & Vegetable oils \\
\hline \multicolumn{2}{|l|}{ Meats/poultry/seafood } \\
\hline Ham, bacon, offal - chicken livers & Fresh and non-processed meats \\
\hline Aged, cured, canned, or marinated meats - pepperoni, salami & Eggs when limited to no more than 3 per week \\
\hline Salted, smoked, and dried fish & Fresh or frozen fish, canned tuna or salmon \\
\hline \multicolumn{2}{|l|}{ Processed meats - hot dogs, bologna } \\
\hline \multicolumn{2}{|l|}{ Pickled herring } \\
\hline \multicolumn{2}{|l|}{ Vegetables } \\
\hline Certain navy beans, pinto beans, pole beans, lentils, garbanzo beans, broad beans & String beans \\
\hline Most peas & Onion when used only for flavoring \\
\hline Sauerkraut, olives, and pickles & $\begin{array}{l}\text { Asparagus, beets, carrots, spinach, tomatoes, squash, corn, } \\
\text { zucchini, broccoli, lettuce, potatoes }\end{array}$ \\
\hline \multicolumn{2}{|l|}{ Grains, breads, cereals } \\
\hline Yeast breads - most white breads & Whole wheat, rye, English muffins, Melba toast, bagels \\
\hline Doughnuts & Most cereals \\
\hline Sourdough & Rice, pasta \\
\hline \multicolumn{2}{|l|}{ Crackers with cheese and pastries containing chocolate or nuts } \\
\hline \multicolumn{2}{|l|}{ Soups } \\
\hline Canned soups & Soups without MSG or yeast \\
\hline \multicolumn{2}{|l|}{ Soup cubes and bouillon cubes with MSG } \\
\hline \multicolumn{2}{|l|}{ Fruits } \\
\hline Figs, raisins, plums, papaya, pineapple, avocados, kiwifruit & Apples, prunes, cherries, grapes, apricots, peaches, pears \\
\hline Citrus fruits, bananas & Limit citrus fruits and bananas to $I / 2$ to I serving per day \\
\hline \multicolumn{2}{|l|}{ Desserts/snack foods } \\
\hline Chocolate, ice cream & Fruits as above, sherbets, ices, sorbets \\
\hline Cookies and cakes made with yeast & cakes/cookies made without yeast \\
\hline Potato chip products & Pretzels \\
\hline \multicolumn{2}{|l|}{ Nuts/seeds, puddings } \\
\hline \multicolumn{2}{|l|}{ Additives } \\
\hline MSG & Wine vinegar \\
\hline Seasonings and spices & Limited use of soy sauce \\
\hline Artificial sweeteners & Small amounts of salad dressing \\
\hline
\end{tabular}

difference between gender and migraine type. The MannWhitney $U$ test was also used to compare the differences between monthly VAS, monthly number of attacks and monthly analgesic consumption of the two groups. Statistical significance was defined as $P<0.05$.

\section{Results}

There were no demographic differences between the cases $(P>0.05)$ (Table 3). VAS scores were lower in Group D than in Group $\mathrm{K}(P<0.01)$, and the migraine attack frequencies and monthly analgesic consumption amounts were also significantly lower $(P<0.01)$ (Table 4$)$.

\section{Discussion}

The pharmacological treatment of migraine may be acute or preventive, and patients who experience frequent severe headache attacks often require both approaches. The contemporary guidelines include few prophylactic drugs under 
Table 3 Demographic values of the patients

\begin{tabular}{llllll}
\hline Group & Age (Year) & Sex $(\mathbf{M} / \mathbf{W})$ & Height $(\mathbf{c m})$ & Weight $(\mathbf{k g})$ & Type* of migraine $(\mathbf{I} / \mathbf{2})$ \\
\hline Group K & $44.61 \pm 12.39$ & $5 / 20$ & $165.79 \pm 7.15$ & $72.49 \pm 12.43$ & $8 / 17$ \\
Group D & $42.02 \pm 10.15$ & $8 / 17$ & $167.35 \pm 9.72$ & $77.41 \pm 14.85$ & $10 / 15$ \\
$P$ values & 0.87 & $>0.05$ & 0.86 & 0.44 & $>0.05$ \\
\hline
\end{tabular}

*Type I, migraine without aura; Type 2, migraine with aura.

the recommendations of Group I on the basis of evidence, scientific effect and clinical assessment. They are: amitriptyline, atenolol, propranolol, flunarizine, and valproate sodium. Group II includes: nonsteroidal anti-inflammatory drugs, specifically naproxen and naproxen sodium as well as lornoxicam; antiepileptic drugs gabapentin, lamotrigine, topiramate; calcium channel blockers verapamil and cinnarizine; selective serotonin reuptake inhibitor fluoxetine; beta-blockers (metoprolol and nadolol); dihydroergotamine and vitamin $\mathrm{B}_{2}{ }^{9}$

How beta-blockers reduce attack frequency in migraneurs is not clear, although it is probably by acting on the central monoaminergic system and serotonin receptors. Not all of these drugs are effective, and those used in migraine prophylaxis include atenolol, metoprolol, nadolol and propranolol. ${ }^{10-15}$

Vitamin $B_{2}$ is a water-soluble essential precursor to flavin mononucleotides necessary for electron transport within the Krebs cycle. It is essential to normal production of ATP and thus for maintaining membrane stability and for all energy-related cellular functions. ${ }^{16} \mathrm{~A}$ mitochondrial dysfunction causing impaired oxygen metabolism may play a role in migraine pathogenesis. Riboflavin at high doses (up to $400 \mathrm{mg}$ ) showed good effectiveness in preventing migraine attacks with a low rate of unwanted side effects, such as mild abdominal pain and diarrhea. ${ }^{17}$

The role of dietary factors in provoking migraine attacks is of increased interest. ${ }^{18-21}$ The role of serotonin (5-HT) in migraine has intrigued investigators observing that the migraine attack is associated with an increased excretion of serotonin metabolites. ${ }^{22}$ Serotonin released from hypersensitive platelets has been suggested as one of the precipitators of the vasoconstrictor phase of migraine. A reduction in platelet serotonin might thus have a beneficial effect.
Such a reduction could theoretically be achieved by a reduced dietary intake of serotonin and the serotonin precursor tryptophan (TRP). ${ }^{23,24} \mathrm{~A}$ carbohydrate-rich meal, with subsequent insulin secretion, increases the availability of TRP to the brain and thereby also the serotonin synthesis in the brain. ${ }^{25}$ TRP is the scarcest of the amino acids and constitutes on average only about $1 / 100$ th of the total amino acid content of proteins. The dietary intake of TRP and protein is usually considerably higher than the required amount. However, an increased serotonin level in the brain is probably helpful in alleviating migraine headache, since serotonin is known to be involved in the anti-nociceptive system. ${ }^{26}$

A variety of amines have been implicated in the development of headache, most commonly tyramine (TYR), histamine (HIS), and beta-phenylethylamine (PEA). ${ }^{27-28}$ Cheeses, peanuts, meats, and alcohol are known to contain TYR, HIS, and PEA. Citrus fruits contain octopamine and synephrine. All of these foods has been implicated clinically to be causally related to headache activity.

One of the most commonly cited food triggers of headache is chocolate. Chocolate is especially rich in a variety of vasoactive amines including PEA, which crosses the bloodbrain barrier and effects cerebral blood flow. Headache may therefore be related to a different metabolism. Theobromine, a methylxanthine found in cocoa that is similar in chemical structure to caffeine may act as a headache trigger. ${ }^{29}$

Many people believe that by avoiding some specific foods it is possible to reduce the frequency of migraine attacks. Putative allergic factors are often considered responsible for migraine attacks, whereas, only in rare cases, a specific food directly causes migraine. By contrast, fasting has been described to be a precipitating factor in $25 \%$ of children and in $40 \%$ of adults affected. Also, some foods are involved as precipitating factors in percentages varying from $10 \%$ to

Table 4 Monthly VAS, number of attacks and analgesic consumption rates of the patients

\begin{tabular}{llll}
\hline Group & Monthly VAS & Monthly number of attacks & Monthly analgesic consumption \\
\hline Group K & $0.88 \pm 0.53$ & $5.15 \pm 1.33$ & $3.64 \pm 0.76$ \\
Group D & $0.44 \pm 0.51$ & $2.70 \pm 1.59$ & $1.88 \pm 0.78$ \\
$P$ values & 0.006 & 0.007 & 0.003 \\
\hline
\end{tabular}


Table 5 Dietary items and chemical migraine triggers ${ }^{7}$

\begin{tabular}{ll}
\hline Food item & Chemical trigger \\
\hline Cheese & Tyramine \\
Chocolate & Phenylethylamine, theobromine \\
Citrus fruits & Phenolic amines, octopamine \\
Hot-dogs, ham, cured meats & Nitrites, nitric oxide \\
Dairy products, yogurt & Allergenic proteins (casein, etc) \\
Fatty and fried foods & Linoleic and oleic fatty acids \\
Asian, frozen, snack foods & Monosodium glutamate \\
Coffee, tea, cola & Caffeine, caffeine withdrawal \\
Food dyes, additives & Tartrazine, sulfites \\
Artificial sweetener & Aspartame \\
Wine, beer & Histamine, tyramine, sulfites \\
Fasting & Stress hormone release, hypoglycemia \\
\hline alce cream headache is probably a cold-induced vasoconstrictor reflex response
\end{tabular}

$45 \%$, namely: chocolate, cheese, some fruits, citrus fruits, fatty foods and fried food..$^{30}$ Table 5 lists potential food items that have been reported to trigger migraine headaches and the chemical constituent thought to be specifically involved in the mechanism of the attack. ${ }^{7}$

Some dietary restriction studies have reported a decrease in headache after participation in an elimination diet. ${ }^{31,32}$ In contrast some studies have found that dietary restriction does not significantly decrease headache ${ }^{33}$ or that placebos are as likely to result in headache as challenge foods. ${ }^{34}$

Peatfield ${ }^{35}$ recorded $19 \%$ of patients reporting sensitivity to cheese, chocolate, or both, and $11 \%$ of patients sensitive to citrus fruits. The exact mechanism of these migraine attacks is unknown, although migraines are believed to be caused by a chemical reaction consisting of the release of serotonin from the intestinal wall, or by an enzymatic defect, and not by allergic reactions.

Peatfield studied 60 patients with migraine - mean duration of migraines was 18 years for women and 22 years for men. When patients were put on an exclusion diet, in most cases, migraines disappeared by the fifth day. The mean number of foods causing symptoms was 10 per patient, the most frequent offenders being wheat, orange, egg, tea and coffee, chocolate and milk, beef, corn, cane sugar, and yeast, mushrooms, and peas. When offending foods were avoided, all patients improved. In fact, the number of headaches fell from 402 to 6 per month, with $85 \%$ of the subjects becoming headache free. ${ }^{35}$

Elimination diets have been shown to be valuable in treating migraine. When 88 children with severe migraines were put on an oligoantigenic diet, 93\% improved. ${ }^{31}$ In another study of 17 patients who completed an elimination diet, migraine attacks were found to be most frequently caused by cow's milk (10 out of the 17). Other culprits included flour, eggs, cheese, pork, and artificial colors and preservatives. ${ }^{36,37}$

In this study we tried to prepare a detailed and strict dietary program that avoided food that is believed to precipitate migraine attacks. In light of the previous studies on this subject patients can also be offered alternative food choices. We believe that avoiding stress is as effective as diet and prophylactic medications in the prevention of headache episodes. The findings of this study revealed decreased severity and frequency of headache episodes and less analgesic consumption in the group that was treated with the dietary list, verifying our hypothesis.

\section{Conclusions}

It was determined that beta-blocker and riboflavin therapy supplied with an appropriate diet (with alternatives) was associated with statistically significant decreases in headache frequency, intensity, duration and medication intake. The prevention of headaches by attention to precipitating factors may be preferable to long-term prophylactic drug treatment with attending adverse reactions.

We once again ascertained in this study that diet is of great importance in migraine treatment. Throughout the course of treatment, we observed many positive effects of an appropriate diet list and its correct application on patients with migraine. We believe more positive results can be achieved if a diet list is attached to prescriptions.

\section{Consent}

Written informed consent was obtained from the patients for the publication of this case report and accompanying images. A copy of the written consent is available for review by the Editor-in-Chief of this journal.

\section{Disclosure}

The author declares that he has no competing interests. BZ presented the case histories, performed case management, drafted the manuscript. The author read and approved the final manuscript.

\section{References}

1. Robert GK. Diagnostic issues in migraine. Curr Pain Headache Rep. 2001;5(2):183-188.

2. Sandrini G, Cecchini AP, Hristova SI, et al. Neurophysiology of migraine. J Headache Pain. 2001;2:S67-S71.

3. Breslau N, Rasmussen BK. The impact of migraine: Epidemiology, risk factors, and co-morbidities. Neurology. 2001;56:4-12.

4. Moschiano F, Grazzi L, D'Amico D, et al. Menstrual migraine. J Headache Pain. 2001;2:117-119.

5. Silberstein SD, Goadsby PJ. Migraine: preventive treatment. Cephalalgia. 2002;22(7):491-512. 
6. Pini LA, Lupo L. Anti-epileptic drugs in the preventive treatment of migraine headache: a brief review. J Headache Pain. 2001;2:13-19.

7. Millichap JG, Yee MM. The diet factor in pediatric and adolescent migraine. Pediatr Neurol. 2003;28(1):9-15.

8. Headache Classification Subcommittee of the International Headache Society. The international classification of headache disorders. Cephalalgia. 2004;24:1-151.

9. Gallai V, Sarchielli P. Diagnostic and therapeutic guidelines for migraine. Italian Society for the Study of Headaches (SISC). J Headache Pain. 2001;2:125-129.

10. Børgesen SE, Nielsen JL, Møller CE. Prophylactic treatment of migraine with propranolol. A clinical trial. Acta Neurol Scand. 1974;50(5): 651-656.

11. Mathew NT. Prophylaxis of migraine and mixed headache. A randomized controlled study. Headache. 1981;21(3):105-109.

12. Andersson PG, Dahl S, Hansen JH, et al. Prophylactic treatment of classical and non-classical migraine with metoprolol: a comparison with placebo. Cephalalgia. 1983;3(4):207-212.

13. Olerud B, Gustavsson CL, Furberg B. Nadolol and propranolol in migraine management. Headache. 1986;26(10):490-493.

14. Forssman B, Lindblad CJ, Zbornikova V. Atenolol for migraine prophylaxis. Headache. 1983;23(4):188-190.

15. Ryan RE Sr, Ryan RE Jr, Sudilovsky A. Nadolol: its use in the prophylactic treatment of migraine. Headache. 1983;23(1):26-31.

16. Evans RW, Taylor FR. "Natural" or alternative medications for migraine prevention. Headache. 2006;46(6):1012-1018.

17. Schoenen J, Jacquy J, Lenaerts M. Effectiveness of high-dose riboflavin in migraine. A randomized controlled trial. Neurology. 1998;50(2): 466-470.

18. Mediana JL, Diamond S. Migraine and atopy. Headache. 1976;15(4): 271-273.

19. Glover V, Littlewood J, Sandler M, et al. Biochemical predisposition to dietary migraine: the role of phenolsulfotransferase. Headache. 1983;23(2):53-58.

20. Monro J, Carini C, Brostoff J. Migraine is a food-allergic disease. Lancet. 1984;2(8405):719-721.

21. Peatfield RC, Glover V, Littlewood JT, et al. The prevalence of dietinduced migraine. Cephalalgia. 1984;4(3):179-183.
22. Sicuteri F, Testi A, Anselmi B. Biochemical investigations in headache: increase in the hydroxy-indole-acetic excretion during migraine attacks. Int Arch Allergy. 1961;19(1):55-58.

23. Anthony M, Hinterberger H, Lance JW. Plasma serotonin in migraine and stress. Arch Neurol. 1967;16(5):544-552.

24. Hilton BP, Cumings JN. 5-hydroxytryptamine levels and platelet aggregation responses in subjects with acute migraine headache. J Neurol Neurosurg Psychiatry. 1972;35(4):505-509.

25. Fernstrom JD. Dietary precursors and brain transmitter formation. Ann Rev Med. 1981;32:413-425.

26. Sicuteri F. Endorphins, opiate receptors and migraine headache. Headache. 1978;17(6):253-257.

27. McCulloch J, Harper AM. Phenylethylamine and cerebral blood flow: possible involvement of phenylethylamine in migraine. Neurol. 1977; 27(9):817-821.

28. McCulloch J, Harper AM. Factors influencing the response of the cerebral circulation to phenylethylamine. Neurol. 1979;29(2):201-207.

29. Tarka SM. The toxicology of cocoa and methylaxantines: a review of the literature. Crit Rev Toxicol. 1982;9(4):275-312.

30. Prophylactic treatment of migraine. J Headache Pain. 2001;2: 147-161.

31. Egger J, Carter CM, Wilson J, et al. Is migraine food allergy? A double-blind controlled trial of oligoantigenic diet treatment. Lancet. 1983;2(8355):865-869.

32. Mansfield LE, Vaughn TR, Waller SF. Food allergy and adult migraine, double-blind and mediator confirmation of an allergic etiology. Ann Allergy. 1985;55:126-129.

33. Kohlenberg RJ. Thyramine sensitivity in dietary migraine: a critical review. Headache. 1982;22(1):30-34

34. Moffett AM, Swash M, Scott DF. Effect of chocolate in migraine: a double-blind study. J Neurol Neurosurg Psychiatry. 1974;37(4): 445-448.

35. Peatfield RC. Relationships between food, wine, and beer-precipitated migrainous headaches. Headache. 1995;35(6):355-357.

36. Grant EC. Food allergies and migraine. Lancet. 1979;2(8138): 358-359.

37. Mylek D. Migraine as one of the symptoms of food allergy. Pol Tyg Lek. 1992;47(3-4):89-91.
Journal of Pain Research

\section{Publish your work in this journal}

The Journal of Pain Research is an international, peer-reviewed, open access, online journal that welcomes laboratory and clinical findings in the fields of pain research and the prevention and management of pain. Original research, reviews, symposium reports, hypothesis formation and commentaries are all considered for publication.

\section{Dovepress}

The manuscript management system is completely online and includes a very quick and fair peer-review system, which is all easy to use. Visit http://www.dovepress.com/testimonials.php to read real quotes from published authors. 